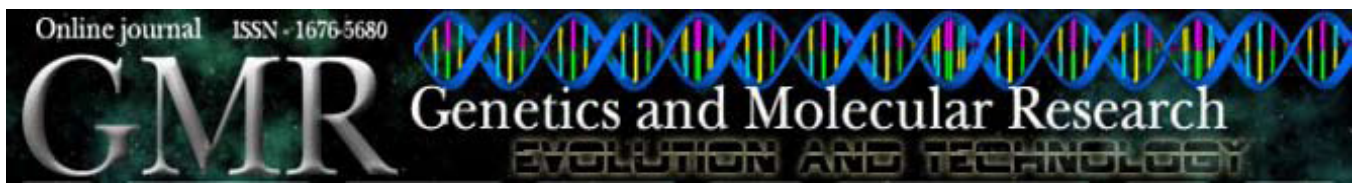

\title{
Gene expression profile of the plant pathogen Fusarium graminearum under the antagonistic effect of Pantoea agglomerans
}

\author{
V. Pandolfi ${ }^{1}$, E.C. Jorge ${ }^{2}$, C.M.R. Melo ${ }^{3}$, A.C.S. Albuquerque ${ }^{4}$ and H. Carrer ${ }^{5}$ \\ ${ }^{1}$ Centro de Energia Nuclear na Agricultura, Universidade de São Paulo, \\ Piracicaba, SP, Brasil \\ 2Departamento de Zootecnia, Escola Superior de Agricultura "Luiz de Queiroz", \\ Universidade de São Paulo, Piracicaba, SP, Brasil \\ ${ }^{3}$ Departamento de Aquicultura, Universidade Federal de Santa Catarina, \\ Florianópolis, SC, Brasil \\ ${ }^{4}$ Departamento de Pesquisa e Desenvolvimento, \\ Empresa Brasileira de Pesquisa Agropecuária, Brasília, DF, Brasil \\ ${ }^{5}$ Departamento de Ciências Biológicas, \\ Escola Superior de Agricultura "Luiz de Queiroz", \\ Universidade de São Paulo, Piracicaba, SP, Brasil \\ Corresponding author: V. Pandolfi \\ E-mail: valescapandolf@gmail.com
}

Genet. Mol. Res. 9 (3): 1298-1311 (2010)

Received March 18, 2010

Accepted May 15, 2010

Published July 16, 2010

DOI 10.4238/vol9-3gmr828

\begin{abstract}
The pathogenic fungus Fusarium graminearum is an ongoing threat to agriculture, causing losses in grain yield and quality in diverse crops. Substantial progress has been made in the identification of genes involved in the suppression of phytopathogens by antagonistic microorganisms; however, limited information regarding responses of plant pathogens to these biocontrol agents is available. Gene expression analysis was used to identify differentially expressed transcripts of the fungal plant pathogen $F$. graminearum under antagonistic effect of the bacterium Pantoea agglomerans. A macroarray was constructed,
\end{abstract}


using 1014 transcripts from an F. graminearum cDNA library. Probes consisted of the cDNA of $F$. graminearum grown in the presence and in the absence of $P$. agglomerans. Twenty-nine genes were either up (19) or down (10) regulated during interaction with the antagonist bacterium. Genes encoding proteins associated with fungal defense and/or virulence or with nutritional and oxidative stress responses were induced. The repressed genes coded for a zinc finger protein associated with cell division, proteins containing cellular signaling domains, respiratory chain proteins, and chaperone-type proteins. These data give molecular and biochemical evidence of response of $F$. graminearum to an antagonist and could help develop effective biocontrol procedures for pathogenic plant fungi.

Key words: Phytopathogen; Microorganism interaction; Macroarray; Gene expression

\section{INTRODUCTION}

The fungus Fusarium graminearum Schwabe [teleomorph: Gibberella zeae (Scw.) Petch] has been reported as the causal agent of Fusarium head blight or scab, which is responsible for major yield and grain quality losses in wheat, maize, barley, and oat (McMullen et al., 1997). Although crop rotation and chemical treatment at flowering time are strategies currently recommended to reduce losses caused by Fusarium head blight, they have not been effective enough in controlling fusarioses. Besides, chemical residues and higher production costs are potential problems associated with chemical treatments (Khan et al., 2001). In wheat, the use of resistant cultivars has been the most advantageous alternative to soften the impact of scab disease (Bernardo et al., 2007). However, the available genetic sources are still limited in wheat as well in other crops. In addition, the wide range of variance in virulence as observed inter- and intra- $F$. graminearum species represents an additional difficulty in the incorporation of resistance genes in plant cultivars (Carter et al., 2002).

An efficient and promising strategy to protect cultivated plants against diseases, including scab, has been the selection of suitable antagonist microorganisms. Therefore, a range of bacterial isolates has been efficiently used as an additional or alternative means for biological control. The bacterium Pantoea agglomerans has been reported to be an effective biological control agent for protecting a number of crop plants from damage induced by several pathogens under both in vitro and field conditions (Özaktan and Bora, 2004). Most studies on phytopathogen biocontrol have addressed a multitude of factors related to how microbial antagonists affect pathogens and what are the mechanisms, metabolites and genes involved in the antagonism. In contrast, responses of plant pathogens to biocontrol agents have received little attention (Duffy et al., 2003).

Diverse molecular tools have been used to study gene expression in response to a great variety of chemical or physical stimuli. Hybridization array technology was developed to identify differentially expressed genes by measuring the relative abundance of mRNA transcribed under a particular condition (Stoughton, 2005). The earliest fungal 
microarray studies were reported in the budding yeast Saccharomyces cerevisiae (DeRisi et al., 1997). Since then, transcriptional analysis has been applied to more than 20 species of filamentous fungi and a number of genes involved in cellular processes - such as metabolism, development, symbiosis, and fungal pathogenesis - have been identified and characterized (reviewed by Breakspear and Momany, 2007). F. graminearum genomics started in the late 90s with the construction of expressed sequence tag (EST) libraries based on in vitro cultivated fungus as well as on plants infected with this phytopathogen. Most of these studies have focused on pathogen genes related to pathogenicity/ mycotoxin production (Gaffoor et al., 2005) and plant genes expressed during host- $F$. graminearum interaction (Bernardo et al., 2007). Despite these efforts, knowledge on pathogen genes associated with the interaction of the fungal pathogen versus antagonist microorganism is still limited.

The objective of the present study was to identify differentially expressed genes in $F$. graminearum under biotic stress induced by the antagonist $P$. agglomerans bacterium, using macroarray analysis. This approach will serve as the basis for a better understanding of the molecular mechanisms involved in the interaction between phytopathogenic fungi and antagonist microorganisms. Further investigation on the functions of the identified genes could provide useful information towards establishing efficient and effective fusariosis management and biocontrol strategies.

\section{MATERIAL AND METHODS}

\section{cDNA macroarray construction}

The membrane-based macroarrays were constructed using a Q-bot robot (Genetix, Queensway, UK) belonging to the Brazilian Clone Collection Center, at São Paulo State University (UNESP), Jaboticabal, SP, Brazil. The membranes contained spotted DNA, in the form of bacterial colonies, of a cDNA library constructed from $F$. graminearum grown for 7 days on $1 / 4$ potato dextrose agar (PDA) medium $(30 \mathrm{~g} / \mathrm{L}$ dextrose; $250 \mathrm{~g} / \mathrm{L}$ peeled and sliced potatoes; $20 \mathrm{~g} / \mathrm{L}$ agar), at $28^{\circ} \mathrm{C}$ and a 16 -h photoperiod. In each nylon membrane, 1014 individual clones were spotted in triplicate, in a layout of 384 blocks, using a 4 x 4 configuration. All contigs and singletons, generated from the clustering and assembly of the 1983 sequenced ESTs, were represented in each array. The acetyl-CoA synthetase and glyceraldehyde 3-phosphate dehydrogenase (GAPDH) clones were randomly spotted in the membranes and were used as positive controls.

\section{Synthesis of the plasmidial probe}

Variation in the amount of DNA in the spots was estimated by hybridizing the filters with an oligonucleotide probe that recognized the sequence of the $\beta$-lactamase gene of the pSPORT 1 vector. This probe was synthesized using the primers 5'-TAGACTGGATGGAGGCGGATAA-3' and 3'-CGCCTATTTCAACGTCCTGGTG-5', in the presence of $\left[\alpha{ }^{3}{ }^{33} \mathrm{P}\right]$-dCTP using the overgo method (Ross et al., 1999). After labeling procedures, probes were purified using Sephadex G-50 columns (GE Healthcare, Piscataway, NJ, USA), according to manufacturer instructions and immediately used to hybridize the macroarray platforms. 


\section{Hybridization and image analysis}

The pre-hybridization and hybridization steps were performed according to Northern blotting protocols described by Sambrook et al. (1989). Hybridization signals on the imaging plates were detected using Storm 860 phosphorimager (GE Healthcare). The image data obtained were imported into the program package Array Vision software, version 8.0 (Copryght ${ }^{\circ}$ Imaging Research Inc., 2003) for spot detection and quantification of hybridization signals.

\section{Antagonism assay and RNA extraction}

Both F. graminearum inoculum and the antagonist bacterium P. agglomerans (Embr. 1494, accession No. ATCC PTA 3460) were isolated from a Brazilian wheat variety and kindly provided by Wilmar Cório da Luz (EMBRAPA - Empresa Brasileira de Pesquisa Agropecuária - Embrapa Trigo, Passo Fundo, RS, Brazil).

The antagonist activity of $P$. agglomerans against $F$. graminearum was determined by using the antibiosis method as described in Da Luz (1990), with few modifications. Mycelialagar disks (5-mm diameter sections) of $F$. graminearum were individually transferred to the center of Petri dishes $\left(15 \mathrm{~cm}\right.$ in diameter) containing $1 / 4$ PDA medium and incubated at $28^{\circ} \mathrm{C}$ for 4 days (to obtain a sufficient amount of fungal mycelia for RNA extraction). After this, the antagonist bacterium was transferred to Petri dishes containing $F$. graminearum culture, in a circular pattern by means of a sterile glass funnel $(10 \mathrm{~cm}$ in diameter). In the present study, this interaction treatment is referred to as $\mathrm{FgI}$ (F. graminearum interaction) and Petri dishes containing only $F$. graminearum were used as controls, and they are here referred to as $\mathrm{FgC}$ (F. graminearum control). Both $\mathrm{FgI}$ and $\mathrm{FgC}$ cultures were incubated for 4 additional days under the previously described conditions. After the total 8-day incubation period on $1 / 4$ PDA medium, fungal mycelia were concurrently sampled from the $\mathrm{FgC}$ and $\mathrm{FgI}$ cultures and were immediately ground in the presence of liquid nitrogen. Total RNA was extracted following the protocol described by Sokolovsky et al. (1990). Total RNA samples were quantified by spectrophotometry and their integrity was confirmed by $1 \%$ agarose gel electrophoresis, with ethidium bromide staining.

\section{cDNA probe synthesis and hybridization}

Total RNA samples from $F$. graminearum, grown in the presence (FgI) and in the absence (FgC) of $P$. agglomerans, were used to synthesize labeled cDNA probes. In brief, $30 \mu \mathrm{g}$ total RNA was reverse transcribed with Superscript II (Invitrogen) using the primer oligo-dT18V (156 pmol), with $50 \mu \mathrm{Ci}\left[\alpha^{-3}{ }^{33} \mathrm{P}\right]-\mathrm{dCTP}(2500 \mathrm{Ci} / \mathrm{mol})$, and unlabeled dATP, dGTP, and dTTP (1 $\mathrm{mM}$ each). After an initial 20-min incubation, unlabeled dCTP was added to a final concentration of $1 \mathrm{mM}$, and the reaction was continued for an additional $40 \mathrm{~min}$, at $42^{\circ} \mathrm{C}$. The probe was purified in Sephadex G-50 columns. A procedure similar to Northern blotting was used for hybridization and image analyses were performed as described by Sambrook et al. (1989).

\section{Statistical analysis}

After scanning, data images were inspected manually and low-quality spots were excluded. 
Genes with expression level close to the background value were discarded and 921 genes (of 1014) were further analyzed. ANOVA models were used to estimate relative gene expression and to account for other sources of variation in the macroarray data (Kerr et al., 2000). A two-step general linear model, as described by Wolfinger et al. (2001), was used to normalize the data and then to detect differentially expressed genes. In the first step, data were normalized using the following model: $y_{i j k l}=\mu+G_{i}+T_{j}+M_{k}+r_{i j k l}$, where $y_{i j k l}$ is the $\log _{2}$ sign intensity (gene expression); $\mu$ is a constant associated with each observation; $G_{i}$ is the effect of gene $i$ ( $i=$ $1, \ldots, 921) ; T_{j}$ is the effect of treatment $j(j=1,2) ; M_{k}$ is the random effect of membrane $k$ ( $k=$ $1, \ldots, 6)$, and $r_{i j k l}$ is the random error associated to each observation. This model considers that $M_{k}$ and $r_{i j k l}$ are idd $N\left(0, \sigma_{k}^{2}\right)$ and $N\left(0, \sigma_{r}^{2}\right)$, respectively, and that $M_{k}$ and $r_{i j k l}$ are independent of each other. In the second step, the residue from this mode, which can be regarded as a crude indicator of relative expression levels, was subjected to the following gene-specific model: $r_{g i j k}$ $=G_{g}+T_{(g) i}+M_{(g i j)}+e_{g i j k}$, where $r_{g i j k}$ is the residual of normalization model; $G_{g}$ is the average effect of the gene $g ; T_{(g) i}$ is the effect of treatment $i$ onto gene $g ; M_{(g i) j}$ is the effect of membrane $j$ in the treatment $i$ and gene $g$, and $e_{\text {oijk }}$ stands for the random error. This model considers that $M_{k}$ and $e_{g i j k}$ are idd $N\left(0, \sigma_{Q}^{2}\right)$ and $N\left(0, \sigma_{e}^{2}\right)$, respectively, and that $M_{k}$ and $e_{g i j k}$ are independent of each other. Data were analyzed using PROC MIXED in SAS (SAS/STAT software, version 9, SAS Institute) and the significance of the differences between expressed sequences was assessed by the Student $t$-test $(\mathrm{P}<0.05)$.

\section{PCR validation of macroarray data (RT-qPCR)}

Differentially expressed genes were selected and the measured induction levels were confirmed using real-time quantitative polymerase chain reaction (RT-qPCR). The housekeeping gene GAPDH was analyzed as an endogenous reference. Gene-specific oligonucleotide primers were designed using the web-based primer picking service (Primer3; http://frodo.wi.mit.edu/primer3/; Rozen and Skaletsky, 2000). Primer digital validation was performed using Netprimer (http://www.premierbiosoft.com/netprimer/netprlaunch/ netprlaunch.html). BLAST short (http://www.ncbi.nlm.nih.gov) was used to ensure that each sequence was unique for the specific target gene.

First-strand cDNA of a previously DNAse I-treated RNA aliquot from the same sample was used to prepare the macroarray library (FgC and FgI), using the SuperScript II First-Strand Synthesis System for RT-PCR (Invitrogen). Total RNA $(5.0 \mu \mathrm{g})$ primed with oligo $(\mathrm{dT})_{18}$ was added to the reaction mixture $(20 \mu \mathrm{L})$, following manufacturer instructions. RT-qPCRs, from reversed-transcribed samples, were conducted in $20-\mu \mathrm{L}$ reactions containing $1 \mu \mathrm{L}$ cDNA (12.5 ng cDNA), $10 \mathrm{mM}$ deoxynucleotide triphosphate mixture, $25 \mathrm{mM} \mathrm{MgCl}, 0.25 \mu \mathrm{L} 20 \mathrm{mg} /$ $\mathrm{mL}$ bovine serum albumin (Roche), 1X DNA Master SYBR Green (LightCycler-DNA Master SYBR Green I kit, Roche, Basel, Switzerland), $2.0 \mu \mathrm{M}$ each of forward and reverse primers, and 1.5 U Platinum Taq DNA polymerase (Invitrogen). Amplification was performed in a LightCycler (Roche). In the control, the cDNA was replaced by sterile distilled water. All samples were preheated at $95^{\circ} \mathrm{C}$ for $5 \mathrm{~min}$ as an initial denaturation, followed by 40 cycles of denaturation at $95^{\circ} \mathrm{C}$ for $10 \mathrm{~s}$, annealing in a range of $55^{\circ}$ to $62^{\circ} \mathrm{C}$ for $5 \mathrm{~s}$, and extension in a range of $65^{\circ}$ to $72^{\circ} \mathrm{C}$ for $18 \mathrm{~s}$. The primer sequences as well as the annealing and extension conditions used in different PCR are shown in Table 1. A melting curve was generated for each sample and the purity of amplified products was assessed. After the reactions, all PCR samples were analyzed by 
agarose gel electrophoresis in order to verify amplification of the target fragments. All samples were amplified in two independent PCRs, as replicates, including a control with no template, and average values were used for quantification. The RT-qPCR data were analyzed using relative quantification, according to the $2^{-\Delta \Delta \mathrm{Ct}}$ method (Livak and Schmittgen, 2001).

Table 1. Gene-specific primers used in real-time quantitative PCR assays.

\begin{tabular}{|c|c|c|c|c|}
\hline EST ID & Sequence (5'-3') (direction) & Length (bp) & Annealing $\left({ }^{\circ} \mathrm{C}\right)$ & Extension $\left({ }^{\circ} \mathrm{C}\right)$ \\
\hline FGEQML1020B04 & $\begin{array}{l}\text { F: CAAGTTCACGAGCGACACC } \\
\text { R: GCTTCCACACCATCAACCA }\end{array}$ & 240 & $60^{\circ} \mathrm{C} / 5 \mathrm{~s}$ & $70^{\circ} \mathrm{C} / 18 \mathrm{~s}$ \\
\hline FGEQML1004B10 & $\begin{array}{l}\text { F: CCAAAGCAGCCCACGAAG } \\
\text { R: GGAACCATCAAGCGGAATGT }\end{array}$ & 176 & $62^{\circ} \mathrm{C} / 5 \mathrm{~s}$ & $72^{\circ} \mathrm{C} / 18 \mathrm{~s}$ \\
\hline FGEQML1023H03 & $\begin{array}{l}\text { F: GCTTTCGCTCTCACCACTTT } \\
\text { R: AACAGCCATTTCCCACATTC }\end{array}$ & 141 & $55^{\circ} \mathrm{C} / 5 \mathrm{~s}$ & $65^{\circ} \mathrm{C} / 18 \mathrm{~s}$ \\
\hline FGEQML1006H09 & $\begin{array}{l}\text { F: ACAGATGCCGAGTGTCGTAG } \\
\text { R: GATGTGACGGAGTGAAAGCA }\end{array}$ & 165 & $55^{\circ} \mathrm{C} / 5 \mathrm{~s}$ & $65^{\circ} \mathrm{C} / 18 \mathrm{~s}$ \\
\hline FGEQML1015B05 & $\begin{array}{l}\text { F: AGGTCTCTGGCATTTTGAGG } \\
\text { R: GGAAGGGAAAGTCTGTGAA }\end{array}$ & 102 & $59^{\circ} \mathrm{C} / 5 \mathrm{~s}$ & $69^{\circ} \mathrm{C} / 18 \mathrm{~s}$ \\
\hline FGEQML1013E02 & $\begin{array}{l}\text { F: GGGACAAGAGACACGAAAGG } \\
\text { R: GACACGGAAGGGGAATGAG }\end{array}$ & 109 & $60^{\circ} \mathrm{C} / 5 \mathrm{~s}$ & $70^{\circ} \mathrm{C} / 18 \mathrm{~s}$ \\
\hline FGEQML1003D01 & $\begin{array}{l}\text { F: GACCTCTTCCTCTGACCCTTG } \\
\text { R: TTGGCGACCTCCCTCTACTT }\end{array}$ & 200 & $60^{\circ} \mathrm{C} / 5 \mathrm{~s}$ & $70^{\circ} \mathrm{C} / 18 \mathrm{~s}$ \\
\hline GAPDH & $\begin{array}{l}\text { F: ACCACCGTCCACTCCTACAC } \\
\text { R: GGCGAACAGTCAAGTCAACA }\end{array}$ & 220 & $60^{\circ} \mathrm{C} / 5 \mathrm{~s}$ & $70^{\circ} \mathrm{C} / 18 \mathrm{~s}$ \\
\hline
\end{tabular}

$\mathrm{F}=$ forward $\mathrm{R}$ = reverse; GAPDH (constitutive control) = glyceraldehyde 3-phosphate dehydrogenase.

\section{RESULTS AND DISCUSSION}

\section{Antagonism assay}

The antagonism effect produced by $P$. agglomerans in $F$. graminearum was evaluated in terms of bacterial suppression of mycelial growth of the fungus on PDA (Figure 1a). Both physiological and morphological alterations in the Fusarium phenotype were visually observed, when compared to Fusarium grown without antagonistic bacterium (Figure 1b).
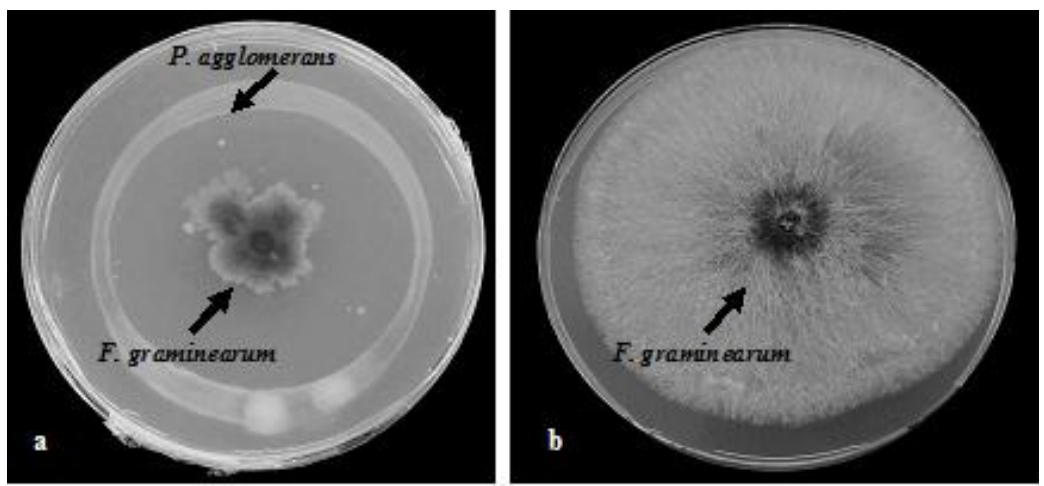

Figure 1. Growth inhibition of Fusarium graminearum caused by the bacterium Pantoea agglomerans (Embr. 1494). The antagonistic activity was determined by the antibiosis method as described in Da Luz (1990). a. FgI $(F$. graminearum $+P$. agglomerans $=$ antagonism $)$. b. $\mathrm{FgC}($ medium containing only $F$. graminearum $=$ control $)$ after a 8 -day-incubation period on $1 / 4$ PDA medium. 
Some strains of $P$. agglomerans have been shown to be efficiently used to control diverse plant diseases caused by different bacterial and fungal pathogens in vitro and under field conditions (Wright et al., 2001; Özaktan and Bora, 2004). However, the mechanism(s) by which P. agglomerans interact with these microorganisms is not clear. Often, more than one mechanism has been described, including antibiosis, parasitism, induced resistance, and competition for nutrients (Lodewyckx et al., 2002). In our in vitro assay, the antagonistic activity observed for $P$. agglomerans against $F$. graminearum did not seem to be related to competition for nutrients, since the inhibition was established in a short period of time (four days) when the nutrients were still available in the media. This suggests that metabolites are produced by the bacterium inhibiting the growth of fungus, since there was no physical interaction between microorganisms. Although in this investigation it was not possible to extract and determine such antifungal agents, previous studies have reported a variety of compounds of microbial origin (e.g., bacteriocins, chitinolytic enzymes, toxic substances, volatiles, and others) that exhibit antagonistic effects (Chernin et al., 1995; Wright et al. 2001).

\section{Differentially expressed transcripts - statistical analysis}

A cDNA macroarray was constructed to study the gene expression pattern of the interaction between F. graminearum and P. agglomerans. After successive hybridizations, 921 transcripts (91\%), of the 1014 F. graminearum spotted onto the array, produced hybridization signs above the background intensity average. In order to determine which of these genes differed significantly in expression, the numeric values corresponding to hybridization signs were analyzed using the statistical methodology proposed by Wolfinger et al. (2001).

Direct visualization of the significance and magnitude of differences in gene expression was possible by using a volcano plot (Figure 2). The contrasting significances shown in

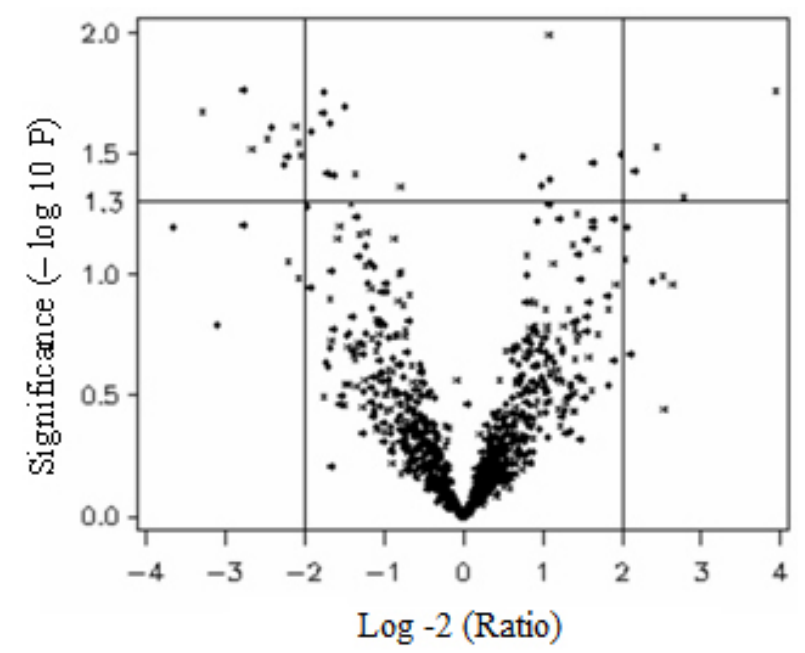

Figure 2. Volcano plot comparison between differential Fusarium graminearum differentially expressed genes in the presence and in the absence of Pantoea agglomerans. The $\mathrm{x}$-axis indicates the differential expression profiles, plotting the fold-induction ratios in a log-2 scale. The $y$-axis indicates the statistical significance of the difference in expression ( $\mathrm{P}$ value from a $t$-test - $\mathrm{P}$ ) in $-\log 10 \mathrm{P}$ scale. The horizontal line represents the test-wise threshold of $\mathrm{P}<0.05$. 
the volcano plot refer to the negative $\log 10$ of the $\mathrm{P}$ value, on the $\mathrm{y}$-axis, versus the estimated difference between the two contrasts, on the x-axis. The reference lines divide the graph into six sections, where the two vertical lines indicate the cut-off point based on four-time differences between contrasts and the horizontal line indicates the cut-off point based on $\mathrm{P}$ value $<5 \%$. Thus, the genes plotted below the horizontal line (884), as well as the genes found in the central (872), right (7) and left (5) sections, do not represent significant differences (low $\mathrm{P}$ value and low difference), while the 29 genes spotted above the horizontal line represent significant differences in expression $(\mathrm{P}<0.05)$.

The major observation made on the volcano plot is that a larger number of genes are up-regulated, with 19 genes plotted on the upper right and central section, while 10 genes plotted on the upper left section are down-regulated (Figure 2). Their nucleotide sequences are available in the dbEST division of GenBank (accession Nos. EX493740 to EX493767, and EX499717).

\section{Differentially expressed transcripts - functional annotation}

The putative function of the 29 differentially expressed genes was determined on the basis of sequence similarity at the $F$. graminearum protein database (Table 2 ) using the functional classification catalogue - FunCat (http://mips.helmholtz-muenchen.de/ proj/funcatDB/search_main_frame.html; Ruepp et al., 2004) provided by the Munich Information Center for Protein Sequences - MIPS (http://mips.gsf.de/) according to general rules developed for $F$. graminearum Genome Database - FGDB (http://mips.helmholtzmuenchen.de/genre/proj/FGDB/; Güldener et al., 2006). Each sequence was searched against the genomic contigs and the predicted genes using the BLAST search algorithm (Altschul et al., 1990). According to this classification, of the 29 differentially expressed transcripts, 20 showed similarity to already known proteins. In the similarity range, six transcripts were classified as "known protein", which were corresponding to previously characterized F. graminearum genes, four were identified as "strong similarity to known protein" (amino acid identity $>60 \%$ ), and ten were "similar to known protein" (amino acid identity between 40 and $60 \%$ ). The remaining nine transcripts showed similarity to unknown protein (3), "no similarity" with any protein (4), and "no hit" on FGDB/MIPS (2). Finally, most ESTs analyzed in this study have not been previously identified and they did not show amino acid similarity to any protein of known function, indicating that available information on functional category based on the bioinformatics analysis is still limited.

\section{Validation of macroarray data by RT-qPCR}

Real-time quantitative PCR was performed in order to validate macroarray data. However, to calculate relative changes using this methodology requires equations to properly analyze the data. The $2^{-\Delta \Delta \mathrm{Ct}}$ method (Livak and Schmittgen, 2001) was used to analyze the relative changes in gene expression data. The quantification is relative because the gene expression value analyzed is normalized in relation to the control gene expression value in the same cDNA sample, such as an untreated control (Pfaffl, 2001). In this study, GAPDH was used as control since it is a housekeeping gene and showed uniform expression on gel and LightCycler experiments and is thus suitable as an internal reference. 
V. Pandolfi et al.

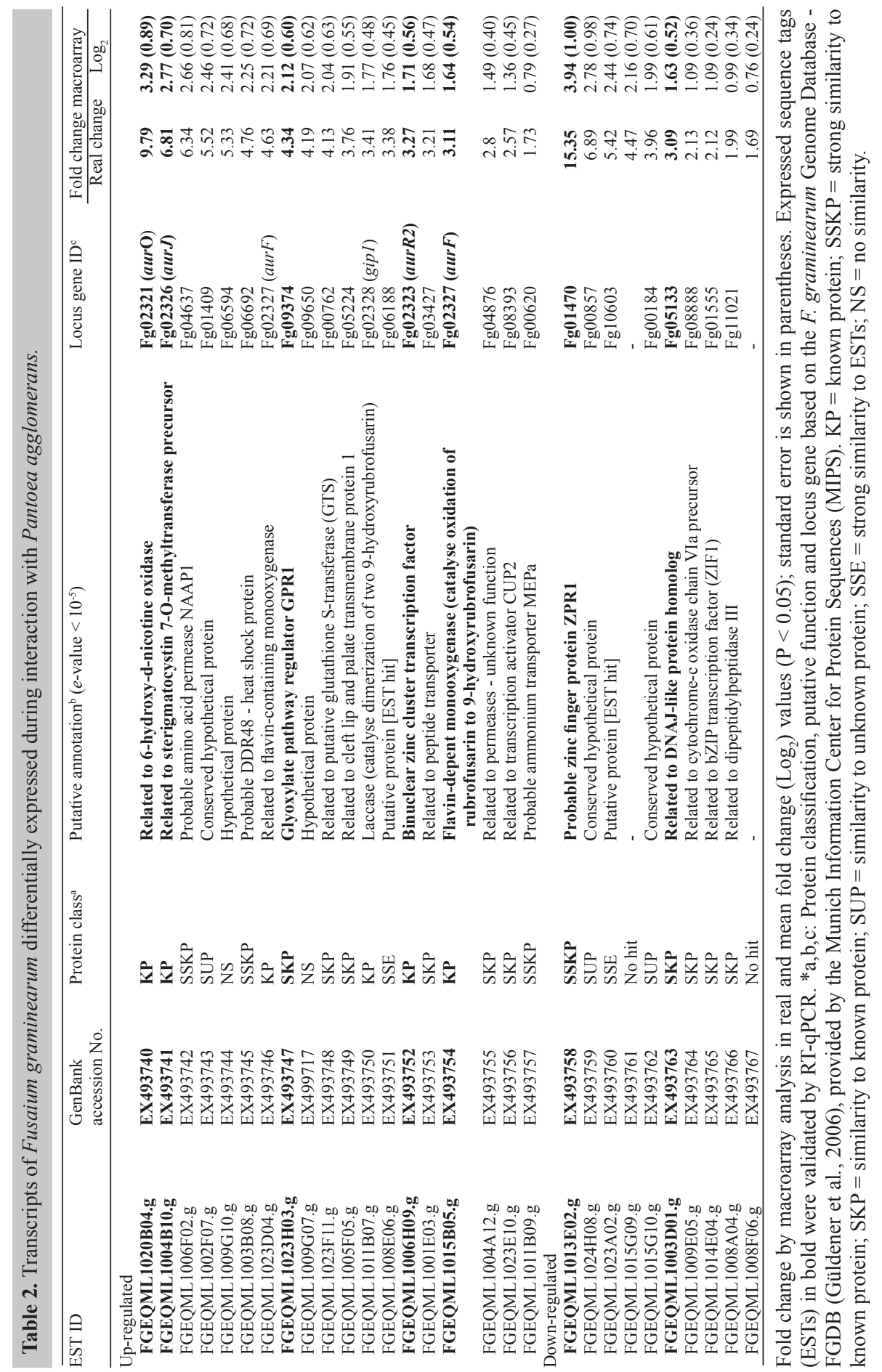

Genetics and Molecular Research 9 (3): 1298-1311 (2010) 
As shown in Table 2, seven differentially expressed transcripts were tested (GenBank accession Nos. EX493740, EX493741, EX493747, EX493752, EX493754, EX493758, and EX493763).

Amplification of gene-specific products was analyzed by melting-curve analysis, followed by agarose gel electrophoresis. In the dissociation curves (temperature versus fluorescence), the $\mathrm{T}_{\mathrm{m}}$ values of the PCR products ranged between $82.4^{\circ}$ and $88.6^{\circ} \mathrm{C}$ for each target gene, and $89.8^{\circ} \mathrm{C}$ for GAPDH. During the 40 amplification cycles, neither nonspecific amplification nor primer-dimer peaks were detected, indicating the specificity of the primers tested. The specificity of gene products was confirmed by the presence of one amplicon per primer-pair tested by agarose gel electrophoresis (data not shown).

Of seven transcripts analyzed, six showed positive correlation between the macroarray and the RT-qPCR data. Among these positively correlated transcripts, five were up-regulated and one was down-regulated when the $F$. graminearum pathogen was under antagonistic interaction from $P$. agglomerans (Table 3). In only one of the transcripts (GenBank accession No. EX493763), the observed change was not consistent between the two techniques. Occasional disagreement between RT-qPCR and hybridization observations can result from cross-hybridization on the macroarray due to transcriptional up-regulation of multiple genes containing similar sequences within a gene family (Sgarlato et al., 2005). In the analysis of seven transcripts based on the RT-qPCR results, the microarray approach produced accurate change differences, with suitable sensitivity to identify differentially regulated transcripts.

\section{Table 3. Validation of macroarray data by real-time quantitative polymerase chain reaction (RT-qPCR).}

\begin{tabular}{llllc}
\hline EST (accession No.) & Gene ID - MIPS & cDNA macroarray* & RT-qPCR & Validation \\
\hline EX493740 & Fg02321 (aurO) & Up $(+3.29)$ & Up $(+1.89)$ & Yes \\
EX493741 & Fg02326 (aur $)$ & Up $(+2.77)$ & Up $(+1.31)$ & Yes \\
EX493747 & Fg09374 & Up $(+2.12)$ & Up $(+2.83)$ & Yes \\
EX493752 & Fg02323 (aurR2) & Up $(+1.71)$ & Up $(+1.33)$ & Yes \\
EX493754 & Fg02327 (aurF) & Up $(+2.21)$ & Up $(+1.23)$ & Yes \\
EX493758 & Fg01470 & Down $(-3.94)$ & Down $(-9.09)$ & Yes \\
EX493763 & Fg05133 & Down $(-1.63)$ & Up $(+1.35)$ & No \\
\hline
\end{tabular}

*The mean fold change values $(\log 2)$ of expression level in Fusarium graminearum compared to $F$. graminearumPantoea agglomerans interactions are presented.

\section{Fusarium graminearum transcript expression analysis after antagonistic bacterium interaction}

\section{Up-regulated transcripts}

The 19 up-regulated transcripts identified in this study (Table 2) revealed a wide range of genes associated with fungal defense and/or virulence systems, in response to nutritional and abiotic stresses. For instance, six F. graminearum up-regulated transcripts (GenBank accession Nos. EX493740, EX493741, EX493746, EX493750, EX493752, and EX493754) belong to the gene cluster responsible for aurofusarin synthesis. Aurofusarin is a secondary metabolite in the naphthoquinone group of polyketides produced by $F$. graminearum and related species (Frandsen et al., 2006). These fungal polyketide pigments are suggested to be associated with important biological functions, including phytotoxic, insecticidal, antibacterial, and fungicidal activities 
(Kim et al., 2005). Furthermore, a report on naphthoquinone produced by Fusarium revealed that the biosynthesis of these compounds is stimulated during growth under extreme conditions, such as nutritional deficiency and/or oxidative stress, resulting in the inhibition or arrest of fungal growth (Medentsev et al., 2005).

The overexpression of those transcripts belonging to a gene cluster already identified in Fusarium and associated with antibacterial function is strong evidence that the stress condition provided by the antagonist $P$. agglomerans triggered the induction of genes associated with fungal defense and pathogenicity. It has been considered that the understanding of pathogen self-defense mechanisms may provide novel approaches to improve disease biocontrol strategies, including the development of transgenes in microorganisms or plants (Duffy et al., 2003).

The DNA damage-inducible protein (DDR) known as DDR48 (GenBank accession No. EX493745) was also up-regulated during the F. graminearum x P. agglomerans interaction. In S. cerevisiae, the expression of DDR48 has been demonstrated to be affected by cellular stresses that promote DNA damage, such as chemical, osmotic and heat shock stresses (Boorsma et al., 2004). In Gibberella fujikuroi, a homologue of the yeast DDR48 protein was up-regulated under nitrogen starvation (Teichert et al., 2004). The present data on DDR48 up-regulation as a response to the inhibition effect of $P$. agglomerans on $F$. graminearum growth, under in vitro culture conditions, are in agreement with the previously reported data on S. cerevisiae and G. fujikuroi. The complexity of factors associated with DDR gene regulation can be associated with the adaptation of this fungus to adverse environmental conditions. Thus, this gene might be a suitable candidate for the discovery of new antifungal agents, since several regulatory systems have been implicated in modulating stress responses.

Evidently, the complete network of regulators, as well as the details of their mode of action, must be better elucidated.

A transcript showing similarity to glutathione S-transferase, GST (GenBank accession No. EX493748), was identified and its expression increased approximately 4-fold in the interaction process. Glutathione S-transferases (EC 2.5.1.18) are a family of multifunctional enzymes that play a role in cellular detoxification and excretion of a wide variety of xenobiotic substances (Hayes et al., 2005). By comparison with other major groups, such as mammals, plants and insects, relatively little is known about GSTs from fungi. It has been reported that GSTs are correlated with fungi defense in response to damage attributed to oxidative stress, xenobiotics, and antifungal compounds (Wang and Ballatori, 1998). Moreover, the ability of several pathogenic fungi to detoxify plant chemical defense agents was demonstrated to be a potential pathogenicity determinant (Sellam et al., 2006). The higher expression of GST in F. graminearum in the presence of the bacterium $P$. agglomerans reveals the importance of studying gene expression profiles in microorganism interaction processes. Interestingly, the GST transcript has also been shown to be associated with plant defense against a variety of toxic substances produced by phytopathogens during the infection process (Kruger et al., 2002).

F. graminearum transcripts similar to amino acid/oligopeptide transporters were also present among the induced genes. Of three identified permeases, one was the NAAP1 (GenBank accession No. EX493742) that is involved in amino acid transport, one was a peptide transporter (GenBank accession No. EX493753), and one transcript was of "un- 
known function", but with an oligopeptide transporter domain (GenBank accession No. EX493755). Together, these three $F$. graminearum transcripts were increased almost 12 fold within the antagonistic treatment as compared to the experimental control without $P$. agglomerans (Table 2). The presence of transcripts identified as permeases and peptide transporters has been associated with fungi nutrient uptake and to survival during hostpathogen interactions (Divon et al., 2005). The induction of these genes apparently is associated with the incorporation of organic nitrogen and with the transcriptional profile of the fungus in response to nutritional stress, corresponding to the transcriptional profile observed during fungal colonization of host plants.

\section{Down-regulated transcripts}

The macroarray analysis revealed that 10 of the F. graminearum transcripts analyzed were down-regulated during interaction with $P$. agglomerans. The putative zinc finger protein - ZPR1 - (GenBank accession No. EX493758) was 15-fold down-regulated during the fungus-antagonist bacterium interaction. Zinc-binding proteins form one of the largest families of transcriptional regulators in eukaryotes, capable of binding DNA and function in a wide range of processes, including regulation of genes involved in the amino acid and vitamin synthesis, carbon and nitrogen metabolism and stress response (MacPherson et al., 2006). In addition, they are involved in the regulation of genes associated with cell division. In mitogen-stimulated cells, ZPR1 interacts with eukaryotic translation elongation factor (ZPR1/eEF-1 $\alpha$ ), with subsequent nuclear redistribution, acting as a signaling molecule in cell proliferation processes (Gangwani, 2006). In S. cereviseae, the disruption of the complex ZPR1/eEF-1 $\alpha$ resulted in slow growth, aberrant morphology and accumulation at the G2/M phase of the cell cycle, showing that ZPR1 may be essential for cell viability and proliferation (Gangwani et al., 1998).

Transcripts related to the cytochrome-c oxidase complex (GenBank accession No. EX493764) and to DNAJ-like protein (GenBank accession No. EX493763) were down-regulated during the $F$. graminearum and $P$. agglomerans interaction. Decreased transcript levels related to the cytochrome-c oxidase complex suggested that respiratory competence is likely to be critical for the fungal defense under antagonistic conditions. The DnaJ is a member of the $40-\mathrm{kDa}$ heat-shock protein family (Hsp40), also known as 'J-protein family of molecular chaperones'. The J domain has been shown to be highly conserved across evolution in both prokaryotic and eukaryotic cells. The structure and function of these proteins have been associated with fundamental biological processes, such as binding of proteins at intermediate stages of folding, assembly and disassembly of proteins, and translation and translocation of proteins and polypeptides across membranes (Walsh et al., 2004). Two repressed transcripts (GenBank accession Nos. EX493761 and EX493767) did not have significant similarity in all searched databases hence they remained unidentified.

Finally, the up- and down-regulated transcripts identified in this study (GenBank accession Nos. EX493743, EX493744, EX499717, EX493751, EX493759, EX493762, and EX493760) together with transcripts without matches in the databases, could represent genes of yet unknown function in pathogen versus antagonist interaction. Most putative transcripts that were induced and repressed showed similarity to proteins associated with fungal defense and/or virulence. The predicted functions of these transcripts suggested that stressed cells se- 
lectively reprogram a wide range of metabolic functions, possibly to save energy by limiting growth-related activities and to synthesize stress-protective molecules. In response to stress, certain genes or groups of genes related to cell stability and integrity are activated as a defense system, but very little is known about the regulation of such mechanisms.

Secondary metabolism has been the object of intense studies in mycotoxigenic fungi, but has been limited to individual pathways and products (primarily mycotoxins). The approach used in this study allowed us to visualize how a plant pathogen responds to antagonistic bacterium and how this can affect the efficiency of biocontrol, representing the first step towards a more comprehensive database. Genomic sequencing has revealed that approximately $30 \%$ of the predicted genes in filamentous fungi are unique to fungi. The predicted function of induced or repressed transcripts of $F$. graminearum under the antagonistic effect of $P$. agglomerans, as identified in this study, represent new information on an important plant pathogen in response to stress mimicking the infection process. The data contribute to a better understanding of genetic and biochemical mechanisms involved in the stress response.

\section{ACKNOWLEDGMENTS}

Research supported by Fundação de Amparo à Pesquisa do Estado de São Paulo (FAPESP) and Conselho Nacional de Pesquisa (CNPq), with assistance from the Empresa Brasileira de Pesquisa Agropecuária, Embrapa Trigo.

\section{REFERENCES}

Altschul SF, Gish W, Miller W, Myers EW, et al. (1990). Basic local alignment search tool. J. Mol. Biol. 215: 403-410.

Bernardo A, Bai G, Guo P, Xiao K, et al. (2007). Fusarium graminearum-induced changes in gene expression between Fusarium head blight-resistant and susceptible wheat cultivars. Funct. Integr. Genomics 7: 69-77.

Boorsma A, Nobel H, Riet B, Bargmann B, et al. (2004). Characterization of the transcriptional response to cell wall stress in Saccharomyces cerevisiae. Yeast 21: 413-427.

Breakspear A and Momany M (2007). The first fifty microarray studies in filamentous fungi. Microbiology 153: 7-15.

Carter JP, Rezanoor HN, Holden D, Desjardins AE, et al. (2002). Variation in pathogenicity associated with the genetic diversity of Fusarium graminearum. Eur. J. Plant Pathol. 108: 573-583.

Chernin L, Ismailov Z, Haran S and Chet I (1995). Chitinolytic Enterobacter agglomerans antagonistic to fungal plant pathogens. Appl. Environ. Microbiol. 61: 1720-1726.

Da Luz WC (1990). Microbiological control of Bipolaris sorokiniana in vitro. Fitopatol. Bras. 15: 246-247.

DeRisi JL, Iyer VR and Brown PO (1997). Exploring the metabolic and genetic control of gene expression on a genomic scale. Science 278: 680-686.

Divon HH, Rothan-Denoyes B, Davydov O, Pietro AD, et al. (2005). Nitrogen-responsive genes are differentially regulated in planta during Fusarium oxyspsorum f. sp. lycopersici infection. Mol. Plant Pathol. 6: 459-470.

Duffy B, Schouten A and Raaijmakers JM (2003). Pathogen self-defense: mechanisms to counteract microbial antagonism. Annu. Rev. Phytopathol. 41: 501-538.

Frandsen RJ, Nielsen NJ, Maolanon N, Sorensen JC, et al. (2006). The biosynthetic pathway for aurofusarin in Fusarium graminearum reveals a close link between the naphthoquinones and naphthopyrones. Mol. Microbiol. 61: 1069-1080.

Gaffoor I, Brown DW, Plattner R, Proctor RH, et al. (2005). Functional analysis of the polyketide synthase genes in the filamentous fungus Gibberella zeae (anamorph Fusarium graminearum). Eukaryot. Cell 4: 1926-1933.

Gangwani L (2006). Deficiency of the zinc finger protein ZPR1 causes defects in transcription and cell cycle progression. J. Biol. Chem. 281: 40330-40340.

Gangwani L, Mikrut M, Galcheva-Gargova Z and Davis RJ (1998). Interaction of ZPR1 with translation elongation factor$1 \alpha$ in proliferating cells. J. Cell Biol. 143: 1471-1484.

Güldener U, Mannhaupt G, Münsterkötter M, Haase D, et al. (2006). FGDB: a comprehensive fungal genome resource on the plant pathogen Fusarium graminearum. Nucleic Acids Res. 34: D456-D458. 
Hayes JD, Flanagan JU and Jowsey IR (2005). Glutathione transferases. Annu. Rev. Pharmacol. Toxicol. 45: 51-88.

Kerr MK, Martin M and Churchill GA (2000). Analysis of variance for gene expression microarray data. J. Comput. Biol. 7: 819-837.

Khan NI, Schisler DA, Boehm MJ, Slininger PJ, et al. (2001). Selection and evaluation of microorganisms for biocontrol of Fusarium head blight of wheat incited by Gibberella zeae. Plant Dis. 85: 1253-1258.

Kim JE, Han KH, Jin J, Kim H, et al. (2005). Putative polyketide synthase and laccase genes for biosynthesis of aurofusarin in Gibberella zeae. Appl. Environ. Microbiol. 71: 1701-1708.

Kruger WM, Pritsch C, Chao S and Muehlbauer GJ (2002). Functional and comparative bioinformatic analysis of expressed genes from wheat spikes infected with Fusarium graminearum. Mol. Plant Microbe Interact. 15: 445-455.

Livak KJ and Schmittgen TD (2001). Analysis of relative gene expression data using real-time quantitative PCR and the 2(- $\Delta \Delta \mathrm{C}(\mathrm{T}))$ method. Methods 25: 402-408.

Lodewyckx C, Vangronsveld J, Porteous F, Moore ERB, et al. (2002). Endophytic bacteria and their potential applications. Crit. Rev. Plant Sci. 21: 583-606.

MacPherson S, Larochelle M and Turcotte B (2006). A fungal family of transcriptional regulators: the zinc cluster proteins. Microbiol. Mol. Biol. Rev. 70: 583-604.

McMullen M, Jones R and Gallemberg D (1997). Scab of wheat and barley: a re-emerging disease of devastating impact. Plant Dis. 81: 1340-1348.

Medentsev AG, Arinbasarova AI and Akimenko VK (2005). Biosynthesis of naphthoquinone pigments by fungi of the genus Fusarium. Prikl. Biokhim. Mikrobiol. 41: 573-577.

Özaktan H and Bora T (2004). Biological control of fire blight in pear orchards with a formulation of Pantoea agglomerans strain Eh 24. Braz. J. Microbiol. 35: 224-229.

Pfaffl MW (2001). A new mathematical model for relative quantification in real-time RT-PCR. Nucleic Acids Res. 29 : e45.

Ross MT, LaBrie S, McPhearson J and Stanton VP (1999). Screening Large-Insert Libraries by Hybridization. In: Current Protocols in Human Genetics (Dracopoli NC, Haines JL, Korf BR, Morton CC, et al., eds.). Wiley, New York, 5.6.1-5.6.32.

Rozen S and Skaletsky HJ (2000). Primer3: Bioinformatics Methods and Protocols. In: Methods in Molecular Biology (Krawetz S and Misener S, eds.). Humana Press, New Jersey, 365-386. Available at [http://frodo.wi.mit.edu/ primer3/]. Accessed March 17, 2006.

Ruepp A, Zollner A, Maier D, Albermann K, et al. (2004). The FunCat, a functional annotation scheme for systematic classification of proteins from whole genomes. Nucleic Acids Res. 32: 5539-5545.

Sambrook J, Fritsch EF and Maniatis T (1989). Molecular Cloning: a Laboratory Manual. 2nd edn. Cold Spring Harbor Laboratory Press, Plainview.

Sellam A, Poupard P and Simoneau P (2006). Molecular cloning of AbGst1 encoding a glutathione transferase differentially expressed during exposure of Alternaria brassicicola to isothiocyanates. FEMS Microbiol. Lett. 258: $241-249$.

Sgarlato GD, Eastman CL and Sussman HH (2005). Panel of genes transcriptionally up-regulated in squamous cell carcinoma of the cervix identified by representational difference analysis, confirmed by macroarray, and validated by real-time quantitative reverse transcription-PCR. Clin. Chem. 51: 27-34.

Sokolovsky V, Kaldenhoff R, Ricci M and Russo VEA (1990). Fast and reliable mini-prep RNA extraction from Neurospora crassa. Fungal Genet. Newsl. 37: 41-43.

Stoughton RB (2005). Applications of DNA microarrays in biology. Annu. Rev. Biochem. 74: 53-82.

Teichert S, Schonig B, Richter S and Tudzynski B (2004). Deletion of the Gibberella fujikuroi glutamine synthetase gene has significant impact on transcriptional control of primary and secondary metabolism. Mol. Microbiol. 53: 1661-1675.

Walsh P, Bursac D, Law YC, Cyr D, et al. (2004). The J-protein family: modulating protein assembly, disassembly and translocation. EMBO Rep. 5: 567-571.

Wang W and Ballatori N (1998). Endogenous glutathione conjugates: occurrence and biological functions. Pharmacol. Rev. 50: 335-356.

Wolfinger RD, Gibson G, Wolfinger ED, Bennett L, et al. (2001). Assessing gene significance from cDNA microarray expression data via mixed models. J. Comput. Biol. 8: 625-637.

Wright SA, Zumoff CH, Schneider L and Beer SV (2001). Pantoea agglomerans strain EH318 produces two antibiotics that inhibit Erwinia amylovora in vitro. Appl. Environ. Microbiol. 67: 284-292. 